\title{
EXTRAÇÃO DE POLISSACARÍDEOS DO BAGAÇO DE UVA COM APLICAÇÃO TECNOLÓGICA
}

\author{
C.BERES ${ }^{1}$, C. MELLINGER-SILVA ${ }^{2}$, S. P. FREITAS ${ }^{3}$ e L. M. C. CABRAL ${ }^{2}$ \\ ${ }^{1}$ Universidade Federal do Rio de Janeiro, Instituto de Química \\ ${ }^{2}$ Embrapa - Agroindústria de Alimentos \\ ${ }^{3}$ Universidade Federal do Rio de Janeiro, Escola de Química
}

E-mail para contato: carolberes@ gmail.com

\begin{abstract}
RESUMO - O objetivo desse trabalho foi avaliar o processo de extração aquosa de polissacarídeos a partir do bagaço de uva tinta Pinot Noir, submetida à vinificação branca. Para seleção dos parâmetros do processo de extração foi realizado um planejamento experimental fatorial com 3 variáveis, 2 níveis e 1 ponto central. As variáveis de processo utilizadas foram: razão solvente/substrato, temperatura e granulometria da farinha. A variável de resposta foi a dosagem de açucares totais pelo método fenol-sulfúrico. $\mathrm{Na}$ farinha do resíduo bruto, as condições determinadas como melhores foram de diluição $10: 1$ e temperatura de $90^{\circ} \mathrm{C}$. A fração solúvel em água foi extraída, liofilizada e analisada quanto ao teor de compostos fenólicos e a atividade antioxidante. Na fração liofilizada, o conteúdo de fenólicos foi de $655,1 \pm 9,5 \mathrm{mg}$ de ácido gálico eq/100g de amostra, enquanto na farinha o teor foi de $325,7 \pm 2,61$. Em relação à atividade antioxidante houve uma manutenção na fração liofilizada $(36,75 \pm 4,8 \mathrm{mMol}$ TEAC/g) quando comparada com a farinha do resíduo bruto $(38,12 \pm 3,68 \mathrm{mMol}$ TEAC/g).
\end{abstract}

\section{INTRODUÇÃO}

A indústria do vinho produz uma grande quantidade de resíduo anualmente, estima-se que a cada 100 litros de vinho branco são gerados aproximadamente $30 \mathrm{Kg}$ de subprodutos, que causam problemas econômicos e ambientais (Silva, 2003). Nos últimos anos, os subprodutos do vinho e do suco de uva têm atraído atenção como uma potencial fonte de compostos fenólicos bioativos, com propriedade antioxidante. Os subprodutos da uva são obtidos depois que as uvas são processadas e o suco é coletado, o material residual composto por semente, casca, polpa e galho, é conhecido como bagaço (Jara-Palacios et al., 2014).

Os compostos fenólicos têm a habilidade de atuar como antioxidantes, por apresentar um mecanismo de retirada de radicais livres. O aumento das evidencias de que esses compostos atuam beneficamente na saúde e no envelhecimento, promove um maior interesse (Mulero et al., 2010; JaraPalacios et al., 2014). As uvas são conhecidamente boas fontes de compostos fenólicos antioxidantes, sendo estes ligados à parede celular polissacarídica da fruta. Os polissacarídeos de parede celular do 


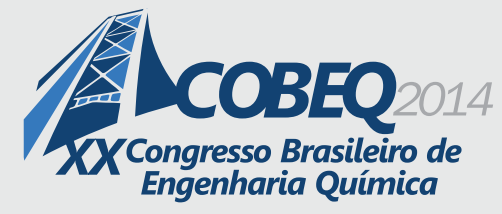

19 a 22 de outubro de 2014

Florianópolis/SC

bagaço da uva, contém grupamentos que possuem a habilidade de formar pontes de hidrogênio e ligações hidrofóbicas com os polifenois (Chamorro et al., 2012). Estudos demonstram que o resíduo da vitivinicultura apresenta um alto conteúdo de compostos fenólicos devido a uma extração incompleta durante a produção do vinho (Rockenbach et al., 2011). Desse modo a extração de polissacarídeos é uma alternativa para liberar os polifenóis ligados na estrutura da parede celular, além de carregar os próprios polissacarídeos que são fibras e podem ser aproveitados no desenvolvimento de produtos, especialmente para fins alimentícios.

A obtenção de polifenóis é realizada tradicionalmente por processos que demandam longos períodos de extração, além de alto consumo de energia e solventes orgânicos, principalmente acetona e metanol. Entretanto, do ponto de vista ambiental a utilização destes solventes está relacionada a problemas como descarte químico, além da necessidade de tratamento posterior do extrato obtido. Desse modo, a extração aquosa tem sido avaliada como uma alternativa mais sustentável para a obtenção de polissacarídeos solúveis (Lazaridou et al., 2008). Portanto, esse trabalho teve por objetivo avaliar o processo de extração de polissacarídeos do bagaço da uva tinta Pinot Noir, resultante do processo de vinificação branca, de modo a obter um extrato seco de polissacarídeos solúveis, com potencial atividade antioxidante, e potencial uso na indústria alimentícia.

\section{MATERIAL E MÉTODOS}

\subsection{Preparo da amostra}

Uma amostra de 5,0 kg (quilograma) de resíduo vitivinícola de uva tinta Pinot Noir, resultante da vinificação branca foi cedida pela vinícola Aurora (Bento Gonçalves - RS). A amostra foi autoclavada por 15 minutos a $120^{\circ} \mathrm{C}$. Em seguida foi realizada a secagem da amostra em estufa a 60 ${ }^{\circ} \mathrm{C}$ por 20 horas, até alcançar peso constante. Com objetivo de separar as sementes do restante do bagaço, foi utilizada uma despolpadeira piloto (Itametal, bonina $0.25 \mathrm{df}$, Brasil) e peneira com orifícios de tamanho $1,5 \mathrm{~mm}$ (milímetros) de diâmetro. Após a separação foram obtidos cerca de $1 \mathrm{~kg}$ de polpa, casca e galhos triturados, nomeado de farinha de resíduo bruto. Para determinação da granulometria da farinha do resíduo bruto foi utilizado um agitador de peneiras, com 7 peneiras de tamanhos 75 a $394 \mu \mathrm{m}$ (micrometros). A farinha foi separada e classificada de acordo com o tamanho da partícula em, fina $(<249 \mu \mathrm{m})$, média $(250$ a $354 \mu \mathrm{m})$ e grossa $(>355 \mu \mathrm{m})$.

\subsection{Extração aquosa}

Foi realizado um planejamento experimental do tipo fatorial com ponto central, com as seguintes variáveis de processo: relação solvente/substrato, temperatura de extração e granulometria da farinha, a variável de resposta utilizada foi a dosagem de açucares totais (tabela 1). O processo de extração foi realizado em banho-maria com agitação (Dubnoff, NT232, Novatécnica, Brasil) por 1 hora, e o solvente utilizado foi água destilada. O conteúdo foi filtrado em quitasato, com filtro de cerâmica e papel de filtro para separação do extrato aquoso e da torta úmida. Os extratos aquosos obtidos foram armazenados em temperatura de $-20^{\circ} \mathrm{C}$ e em seguida liofilizados para retirada total da água. $\mathrm{O}$ extrato liofilizado foi utilizado para as análises subseqüentes. 
Tabela 1 - Valores experimentais e níveis das variáveis independentes usados no planejamento experimental para extração da fração solúvel da farinha do resíduo bruto da uva tinta Pinot Noir.

\begin{tabular}{c|ccc}
\hline \multirow{2}{*}{ Níveis codificados } & \multicolumn{3}{|l}{ Níveis não condificados } \\
\cline { 2 - 4 } & Razão solvente/substrato & Granulometria & Temperatura \\
\hline-1 & $8: 1$ & Fina $(<249 \mu \mathrm{m})$ & $80^{\circ} \mathrm{C}$ \\
0 & $10: 1$ & Média $(250$ a $354 \mu \mathrm{m})$ & $90^{\circ} \mathrm{C}$ \\
+1 & $12: 1$ & Grossa $(>355 \mu \mathrm{m})$ & $100^{\circ} \mathrm{C}$ \\
\hline
\end{tabular}

\subsection{Dosagem de açúcar total}

As dosagens de carboidratos totais foram realizadas pelo método do fenol-ácido sulfúrico, o qual apresenta sensibilidade de 8 a $70 \mu \mathrm{g}$ de açúcar (Dubois et al., 1956). O complexo colorido, resultante, foi lido a $490 \mathrm{~nm}$ em espectrofotômetro marca Bioespectro modelo SP-220. As análises foram realizadas em triplicata, utilizando $10 \mathrm{mg}$ da amostra solubilizada em $50 \mathrm{~mL}$ de água destilada, $0,5 \mathrm{~mL}$ de fenol $5 \%(\mathrm{p} / \mathrm{v})$ e $2,5 \mathrm{~mL}$ de ácido sulfúrico (P.A.).

\subsection{Determinação de fenólicos totais}

A análise foi realizado na farinha do resíduo bruto antes da distribuição granulométrica e no extrato aquoso liofilizado do experimento onde observou-se as melhores condições de extração. Para a quantificação dos compostos fenólicos totais foi realizada uma extração prévia em solução de acetona a $70 \%$ por 30 minutos, seguida por filtração. O filtrado foi diluído 10 vezes em água destilada e este seguiu para a quantificação de acordo com o método espectrofotométrico proposto por Georgé et al. (2005). A quantificação dos compostos fenólicos totais foi realizada por meio de uma curva de calibração de ácido gálico, sendo os valores expressos em mg (miligrama) equivalentes de ácido gálico.100 g-1 de amostra.

\subsection{Determinação de atividade antioxidante pelo método Trolox Equivalente}

A análise foi realizado na farinha do resíduo bruto antes da distribuição granulométrica e no extrato aquoso liofilizado do experimento onde observou-se as melhores condições de extração. Para determinação da atividade antioxidante da farinha do resíduo bruto e da fração liofilizada, foram preparados extratos de acordo com a metodologia descrita por Rufino et al. (2007). A leitura do resultado é realizada em espectrofotômetro, no comprimento de onda de 734nm (nanômetros), após a adição de $3 \mathrm{~mL}$ da solução ABTS (2,2'-azino-bis(3-etilbenztiazoline-6-ácido sulfônico)). 


\section{RESULTADOS E DISCUSSÃO}

\subsection{Extração aquosa de polissacarídeos solúveis da farinha do resíduo bruto da uva}

O planejamento proposto foi realizado para farinha do resíduo bruto, e os resultados foram expressos em valores de absorbância a $490 \mathrm{~nm}$, referente à dosagem de açúcares totais pela metodologia de fenol-sulfúrico, conforme ilustrado na tabela 2.

Tabela 2 - Planejamento experimental completo com ponto central para extração da fração solúvel da farinha do resíduo bruto da uva tinta Pinot Noir.

\begin{tabular}{ccccc}
\hline Experimento & $\begin{array}{c}\text { Razão } \\
\text { Solvente/substrato }\end{array}$ & $\begin{array}{c}\text { Granulometria } \\
(\text { micrometros) }\end{array}$ & $\begin{array}{c}\text { Temperatura } \\
\left({ }^{\mathbf{0}} \mathbf{C}\right)\end{array}$ & $\begin{array}{c}\text { Abs. Açúcar } \\
\text { total (resíduo } \\
\text { bruto) }\end{array}$ \\
\hline $\mathbf{1}$ & -1 & -1 & -1 & 0.331 \\
$\mathbf{2}$ & -1 & 1 & -1 & 0.393 \\
$\mathbf{3}$ & 1 & -1 & -1 & 0.240 \\
$\mathbf{4}$ & 1 & 1 & -1 & 0.330 \\
$\mathbf{5}$ & -1 & -1 & 1 & 0.383 \\
$\mathbf{6}$ & -1 & 1 & 1 & 0.398 \\
$\mathbf{7}$ & 1 & -1 & 1 & 0.342 \\
$\mathbf{8}$ & 1 & 1 & 1 & 0.391 \\
$\mathbf{9}$ & 0 & 0 & 0 & 0.425 \\
$\mathbf{1 0}$ & 0 & 0 & 0 & 0.474 \\
$\mathbf{1 1}$ & 0 & 0 & 0 & 0.408 \\
\hline
\end{tabular}

Abs.: absorbância

No gráfico de Pareto (figura 1), as variáveis temperatura e razão solvente/substrato influenciam significativamente de forma positiva no rendimento da extração aquosa de polissacarídeos do resíduo bruto. O resultado obtido em relação à temperatura no processo de extração de polissacarídeos está de acordo com o esperado (Sun et al., 2010), já que a utilização de maior temperatura aumenta a solubilidade do substrato, permitindo uma maior interação com o solvente utilizado, além de permitir um afrouxamento dos polissacarídeos entrelaçados na ultraestrutura da parede celular. $\mathrm{O}$ aumento desta interação, permite uma maior extração de compostos solúveis em água. O resultado obtido neste trabalho está de acordo com o estudo de Zhu e Liu (2013), no qual os autores determinaram que a melhor temperatura para extração aquosa de polissacarídeos é $95^{\circ} \mathrm{C}$. Da mesma forma, quanto maior a quantidade de solvente, maior a capacidade de solubilização do substrato no meio, isso ocorre devido ao aumento da difusão do solvente na célula, e o aumento da dessorção do polissacarídeo da parede celular. Entretanto, observa-se que na razão solvente/substrato máxima utilizada (12:1), não houve um aumento da extração. Esse fato pode estar relacionado com o alcance do limite do fenômeno de difusão da água e a capacidade de retirada dos polissacarídeos de parede celular removíveis com água 


\section{LCOBEQ 2014

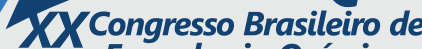 Engenharia Química}

a quente. Desse modo a razão de 10:1, foi a melhor dentre as analisadas, para extração de polissacarídeos solúveis em água, da farinha do resíduo bruto da uva tinta Pinot noir.

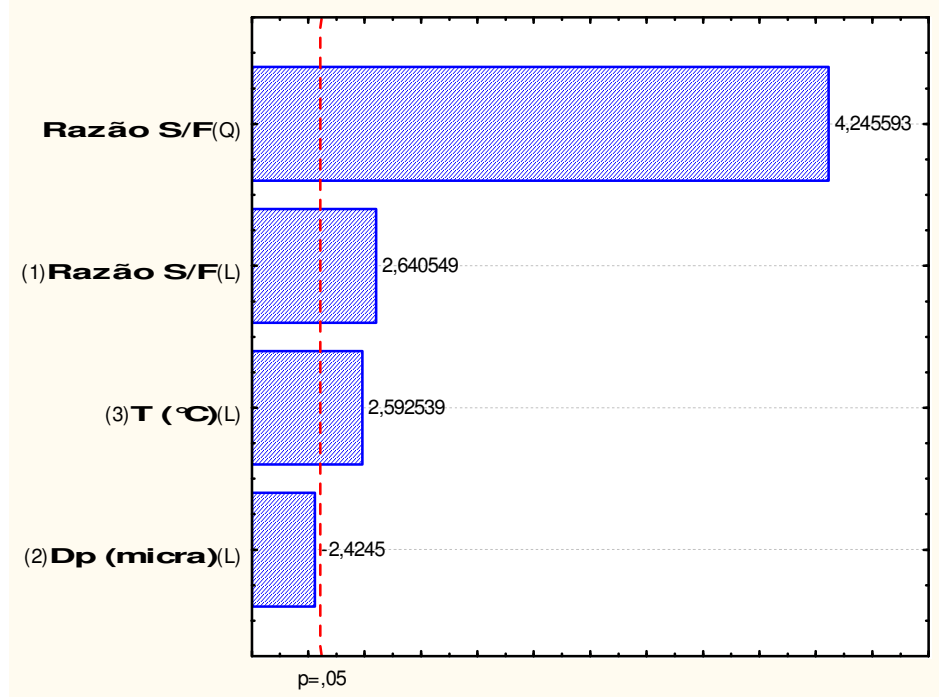

Figura 1- Gráfico de Pareto para determinação da influência das variáveis dependentes na extração aquosa da farinha do resíduo bruto da uva tinta Pinot Noir.

Na figura 2, pode-se observar que as condições operacionais onde se obteve a melhor extração de polissacarídeos solúveis da farinha do resíduo bruto, foi na temperatura de $90{ }^{\circ} \mathrm{C}$ e na razão solvente/substrato de 10:1, lembrando que a granulometria não apresenta influência significativa no resultado. Uma hipótese que justifica o fato das diferenças de tamanho de partículas não influenciarem na eficiência da extração, é a capacidade da água de permear igualmente nos diferentes tamanhos de partículas. 


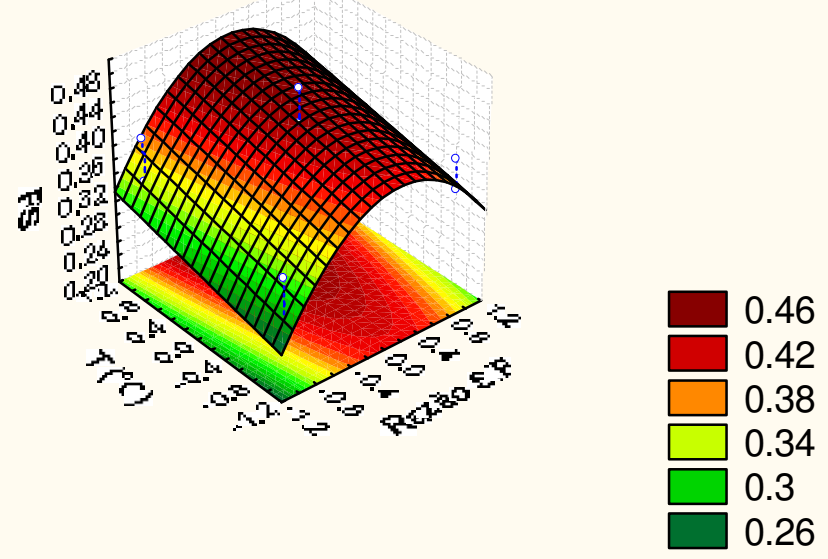

Figura 2- Superfície de resposta para extração aquosa da farinha do resíduo bruto da uva tinta Pinot Noir, em relação à razão solvente/substrato e a temperatura. $\mathrm{O}$ fator granulometria foi fixado no ponto médio (média). FS: dosagem fenol-sulfúrico; Razão S/F: razão solvente/substrato T: temperatura; Dp: granulometria em micrometros.

A determinação de fenólicos totais e da atividade antioxidante foi realizada na fração solúvel liofilizada e na farinha do resíduo bruto, como ilustrado na tabela 3. Foi observado um aumento de aproximadamente 2 vezes, do teor de fenólicos no extrato liofilizado em relação à farinha do resíduo bruto, e uma manutenção da atividade antioxidante. O processo de extração aquosa permite um maior acesso aos compostos fenólicos, através da modificação na conformação promovida pela alta temperatura e pela água, permitindo uma interação com os polímeros, liberando as moléculas mais solúveis para o meio de extração. Esse fator justifica o aumento do teor de fenólicos no extrato liofilizado. O resultado observado foi semelhante ao encontrado por Chamarro et al. (2012), onde após a aplicação de um tratamento enzimático com consequente degradação parcial da ultraestrutura da parede celular, obteve um aumento na detecção do teor de fenólicos.

Tabela 3 - Dosagem de fenólicos totais e determinação da atividade antioxidante da farinha do resíduo bruto, e no extrato liofilizado obtido após a extração aquosa.

\begin{tabular}{lcc}
\hline \multicolumn{1}{c}{ Amostra } & $\mathbf{F T}^{\mathbf{1}}$ & $\mathbf{A A}^{\mathbf{2}}$ \\
\hline Farinha do resíduo bruto & $325,7 \pm 2,61^{\mathrm{a}}$ & $38,12 \pm 3,68^{\mathrm{a}}$ \\
Extrato liofilizado do resíduo bruto & $655,1 \pm 9,50^{\mathrm{b}}$ & $36,75 \pm 4,80^{\mathrm{a}}$ \\
\hline
\end{tabular}

$\mathrm{FT}^{1}$ - Fenólicos Totais expresso em mg de ácido gálico eq/100g de amostra; $\mathrm{AA}^{2}$ - Atividade antioxidante expressa em mMol TEAC/g. Letras diferentes na mesma coluna indicam diferença significativa com intervalo de confiança de $95 \%$, por teste t.

As uvas orgânicas são consideradas superiores em relação à sua atividade antioxidante. Em um estudo comparativo (Mulero et al., 2010), entre uvas orgânicas e uvas convencionais, foi determinado que as cascas de uvas orgânicas apresentam um maior poder antioxidante do que a 


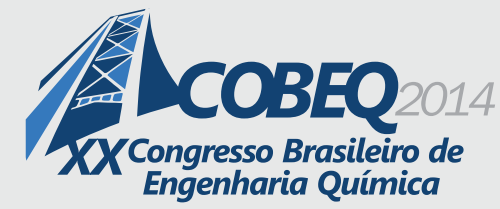

encontrada nas cascas de uvas convencionais. Os resultados encontrado neste trabalho são superiores aos encontrados por Mulero e colaboradores (2010), desse modo a uva tinta Pinot noir analisada neste trabalho apresenta características antioxidantes superiores à uvas orgânicas avaliadas pelo autor citado. A manutenção da atividade antioxidante, sugere que mesmo após os processamentos aos quais as amostras foram submetidas, não houve perda dessa atividade, com concentração de compostos com atividade antioxidante como os fenólicos.

Deve-se levar em consideração que as concentrações dos compostos na uva, e consequentemente no bagaço da uva, variam de acordo com a variedade da uva, suas condições de cultivo, umidade, solo e intensidade de radiação solar (Rondeau et al., 2013). Os resultados deste trabalho foram comparados com um estudo (Rockenbach et al., 2011) onde foram analisados bagaços de uvas da mesma região da uva tinta Pinot noir utilizada neste trabalho, entretanto com cultivares distintos. Em relação ao teor de fenólicos totais e a atividade antioxidante, os resultados encontrados por Rockenbach e colaboradores (2011) foram inferiores aos aqui encontrados.

\section{CONCLUSÃO}

O resíduo bruto obtido a partir do bagaço da uva tinta Pinot noir, apresentado neste trabalho demonstra uma possibilidade de aplicação na indústria. $\mathrm{O}$ extrato liofilizado resultante da extração aquosa representa uma fração polissacarídica rica em compostos fenólicos, com possível utilização como fibra alimentar com atividade antioxidante. No atual cenário, onde os consumidores são influenciados pela qualidade alimentar do produto e seus benefícios na saúde, o aproveitamento do resíduo vitivinícola para a elaboração de um produto com potencial tecnológico, demonstra as possibilidades de avanço deste estudo.

\section{REFERENCIAS}

CHAMORRO, S.; VIVEROS, A.; ALVAREZ I.; VEJA, E.; BRENES, A. Changes in polyphenol and polysaccharides content of grape seed extract and grape pomace after enzymatic treatment. Food Chemistry. v. 133, 308-314, 2012.

DUBOIS, M.; GILLES, K.A.; HAMILTON, J. K.; REBERS, P. A.; SMITH F. Colorimetric method for determination of sugar and related substances. Analitical Chemistry. v. 28, p. 350-356, 1956.

GEORGÉ, S. P.; BRAT, P.; ALTER, P.; AMIOT, M. J. Rapid determination of polyphenols and vitamin C in plant-derived products. Journal of Agricultural and Food Chemistry. v.29 p. 1370$1373,2005$. 
JARA-PALACIOS, M.J.; HERNANZ, D.; GONZÁLEZ-MANZANO, S.; SANTOS-BUELGA, C.; ESCUDERO-GILETE, M.L.; HEREDIA, F.J. Detailed phenolic composition of White grape byproducts by RRLC/MS and measurement of the antioxidant activity. Talanta. v.125, 51-57, 2014.

LAZARIDOU, A.; CHORNICK, T.; BILIADERIS, C.G.; IZYDORCZYK, M.S. Composition and molecular structure of polysaccharides released from barley endosperm cell walls by sequential extraction with water, malt enzymes, and alkali. Journal of Cereal Science. v. 48, p. 304-318, 2008.

MULERO, J.; PARDO, F.; ZAFRILLA, P. Antioxidant activity and phenolic composition of organic and conventional grapes and wines. Journal of Food Composition and Analysis. v.23, p.569-574, 2010.

RONDEAU, P.; GAMBIER, F.; JOLIBERT, F.; BROSSE, N. Compositions and chemical variability of grape pomaces from French vineyard. Industrial Crops and Products. v. 43, p. 251-254, 2013.

ROCKENBACH, I.I.; RODRIGUES, E.; GONZAGA, L. V.; CALIARI, V.; GENOVESE, M.I.; GONÇALVES, A.E.S.S.; FETT, R. Phenolic compounds content and antioxidant activity in pomace from selected red grapes (Vitis vinifera L. and Vitis labrusca L.) widely produced in Brazil. Food Chemistry. v. 127, p. 174-179, 2011.

RUFINO, M.S.M.; ALVES, R.E.; BRITO, E.S.; MORAIS, S.M.; SAMPAIO, C.G.; PÉREZJIMÉNEZ, J.; SAURA-CALIXTO, F.D. Metodologia Científica: Determinação da atividade antioxidantes total em frutas pela captura do radical livre $\mathrm{ABTS}^{\circ+}$. Comunicado Técnico 128. Ministério da Agricultura, Pecuária e Abastecimento. ISSN 1679-6535, 2007.

SILVA, M.L.L.R. Caracterização dos produtos da vinificação. Millenium-Revista ISPV. p. 123-133, 2003.

SUN, Y.; LI, T.; YAN, J.; LIU, J. Technology optimization for polysaccharides (POP) extraction from the fruiting bodies of Pleurotus ostreatus by Box-Benhken statistical design. Carbohydrate Polymers. v. 80, p. 242-247, 2010.

ZHU, C.; LIU, X. Optimization of extraction process of crude polysaccharides from Pomegranate peel by response surface methodology. Carbohydrate Polymers. v. 92, p. 1197-1202, 2013. 